\section{British Council Representative for China}

THE British Council has appointed Prof. P. M. Roxby, professor of geography at the University of Liverpool and a specialist on Far Eastern matters, to be its principal representative in China. He will take up his duties in the early part of 1945. Prof. Roxby has visited China on three occasions : during 1912-13 as Albert Kahn Travelling Fellow ; during 1921-22 as a member of the China Education Commission; and in 1931 as a member of the British group of the Institute of Pacific Relations. His works on China include "The Far Eastern Question in its Geographical Setting", "China as an Entity : The Comparison with Europe", "The Terrain of Early Chinese Civilisation", "China" (Oxford Pamphlets on World Affairs), and contributions on China in the Encyclopædia Britannica. Prof. Roxby's wife, who is lecturer in history at the University of Liverpool, will accompany him to China. With Prof. Roxby's appointment the British Council hopes to be able to expand its work in China, in co-operation with the Chinese authorities. Many valuable activities are already in progress there, particularly in the scientific field, under the direction of Dr. Joseph Needham, who went out to China for the British Council in October 1942.

\section{Summer Schools in Health Education}

The Central Council for Health Education intends holding two Summer Schools during 1944. One will take place at Whitelands College, Bede College, Durham, during July 24-August 3, and the other at Chelsea Polytechnic, London, during August 9-19. The programme of the schools will cover all aspects of health education (including sex education) and should be of value to teachers, youth leaders, educational and medical administrators, nurses and health visitors, social and industrial welfare workers, etc. The mornings will be devoted to lectures which will lay the necessary foundation of basic knowledge, while the evening lectures will relate this knowledge to a wider philosophical, historical and social context. In the afternoons there will be demonstrations and discussions arranged by the various organizations specializing in different fields of health education, and seminars for students with particular interests. Many applicants had to be rejected from the 1943 School owing to lack of accommodation. Those wishing to receive early notification of the forthcoming schools should send their name and address on a postcard to the Central Council for Health Education, Tavistock House, Tavistock Square, London, W.C.1.

\section{Summer School in Social Biology}

The British Social Hygiene Council will be holding a Summer School in Social Biology at the University College of North Wales, Bangor, during August 19 September 2. The theme of the School will be "Social Biology and the Extra School Year". It is planned to throw light upon the aims and content of biology in the school curriculum, with special reference to the coming increase in the school-leaving age. While primarily intended for those responsible for pupils aged 11-15, the School is designed to appeal to all types of teachers, and to people who are interested in education and social questions generally. The morning instructional lectures will be given by a team of experienced lecturers who have assisted at similar summer schools in the past. The evening meetings will be reserved for the addresses of dis- tinguished scientific and social workers upon the broader applications of biology to human life and culture. In keeping with the lecture programme, demonstrations in practical biology will be arranged to suit the needs of teachers working under school conditions. For those who require it, training in the dissection of common animal types will be given. Times will be set aside for seminars and discussions. Further information can be obtained from the British Social Hygiene Council, Tavistock House South, Tavistock Square, London, W.C.1.

\section{The Night Sky in April}

FULL moon occurs on April 8d. 17h. 22m. U.T., and new moon on April 22d. 20h. 43m. The following conjunctions with the moon take place: April 3d. 14h., Jupiter $0 \cdot 1^{\circ} \mathrm{S}$; April 21d. I1h., Venus $3^{\circ}$ N. ; April 26d. 12h., Saturn $2^{\circ}$ N. ; April 28d. 09h., Mars $3^{\circ}$ N. ; April 30d. 21h., Jupiter 0.4 $4^{\circ}$. The following occultations of stars brighter than magnitude 6 take place: April 5d. 22h. 26.8m., 308 $B$ Loon. (D) ; April 6d. 22h. 51.7m., $b$ Virg. $(D)$. The times refer to Greenwich and $D$ refers to disappearance. Mercury attains its greatest eastern elongation on April 12. The planet sets at 19h. 5lm., $20 \mathrm{~h}$. $51 \mathrm{~m}$. and $19 \mathrm{~h} .42 \mathrm{~m}$. at the beginning, middle and end of the month and can be seen as an evening star, but is not very well placed for observation. Venus rises at $5 \mathrm{~h} .13 \mathrm{~m}$. and $4 \mathrm{~h} .20 \mathrm{~m}$. at the beginning and end of the month and can be seen as a morning star. Mars sets at $1 \mathrm{~h} .58 \mathrm{~m}$. and $1 \mathrm{~h}$. at the beginning and end of the month and can be seen in the early part of the night. Jupiter sets at $4 \mathrm{~h}$. $10 \mathrm{~m}$. and $2 \mathrm{~h} .15 \mathrm{~m}$. at the beginning and end of the month, and is stationary on April 13. Saturn sets at $0 \mathrm{~h} .46 \mathrm{~m}$. and $23 \mathrm{~h} .04 \mathrm{~m}$. at the beginning and end of the month. The Lyrid meteor shower is active from April 18-22. These meteors are due to the debris of Comet Thatcher (186I i).

\section{Announcements}

The Royal Society, from the income of a fund bequeathed to it by the late Edward Thomas Browne for the support of marine expeditions and of pure marine research work, has placed the sum of $£ 1,000$ at the disposal of the Allied Control Commission, to be used in the present emergency for the maintenance of the staff and equipment of the Zoological Station at Naples.

THE Society of the Sigma $\mathrm{Xi}$, the well-known American scientific society, founded at Cornell University in 1886 for the "encouragement of Original Investigation in Science, Pure and Applied", with local members organized as chapters or clubs in some hundred and twenty-five American universities and colleges, is extending its activities to nonacademic research institutions which qualify because of their participation in, and encouragement of, original research in science. The first industrial research group to qualify and be granted affiliation with Sigma Xi is the Esso Research Club, of Elizabeth, N.J., the membership of which is drawn from the chemists, physicists, engineers and other technical research and development personnel of the companies associated with Standard Oil Company (N.J.).

Erratum.-In Nature of March 11, p. 319, paragraph on "Meiosis in the Striped Hamster", the number of chromosomes should be $2 n=14$, not $2 n=24$ as printed. 